\title{
Fuzzy Control of Cold Storage Refrigeration System with Dynamic Coupling Compensation
}

\author{
Xiliang Ma $\mathbb{D}^{1,2}$ and Ruiqing Mao ${ }^{1}$ \\ ${ }^{1}$ Xuzhou Institute of Technology, Xuzhou, Jiangsu 221111, China \\ ${ }^{2}$ School of Mechanical and Electrical Engineering, China University of Mining and Technology, Xuzhou, Jiangsu 221116, China \\ Correspondence should be addressed to Xiliang Ma; xlma818@sina.com
}

Received 16 October 2017; Revised 7 January 2018; Accepted 12 February 2018; Published 13 March 2018

Academic Editor: Enrique Onieva

Copyright (c) 2018 Xiliang Ma and Ruiqing Mao. This is an open access article distributed under the Creative Commons Attribution License, which permits unrestricted use, distribution, and reproduction in any medium, provided the original work is properly cited.

Cold storage refrigeration systems possess the characteristics of multiple input and output and strong coupling, which brings challenges to the optimize control. To reduce the adverse effects of the coupling and improve the overall control performance of cold storage refrigeration systems, a control strategy with dynamic coupling compensation was studied. First, dynamic model of a cold storage refrigeration system was established based on the requirements of the control system. At the same time, the coupling between the components was studied. Second, to reduce the adverse effects of the coupling, a fuzzy controller with dynamic coupling compensation was designed. As for the fuzzy controller, a self-tuning fuzzy controller was served as the primary controller, and an adaptive neural network was adopted to compensate the dynamic coupling. Finally, the proposed control strategy was employed to the cold storage refrigeration system, and simulations were carried out in the condition of start-up, variable load, and variable degree of superheat, respectively. The simulation results verify the effectiveness of the fuzzy control method with dynamic coupling compensation.

\section{Introduction}

Automatic control of cold storage refrigeration system is an important means to save energy and improve the quality of refrigeration $[1,2]$. The automatic control can guarantee the stability of the storehouse temperature, avoid the unnecessary low temperature, and keep the temperature, pressure, liquid level, and other state parameters, which ensure the safety and efficiency of the system, in the required range. However, cold storage refrigeration systems possess the characteristics of multi-input and multi-output and strong coupling, which brings challenges to the dynamic modeling and the controller design $[3,4]$.

In the traditional control process of cold storage refrigeration system, the compressor, condenser, evaporator, expansion valve, and other main components are controlled separately [5]. Although those methods realize the automatic control of cold storage refrigeration system, it is difficult to achieve higher precision adjustment requirements because of ignoring the coupling. On the other hand, it is difficult to apply to the system with large change of loads and working conditions [6]. With the improvement of the refrigeration effect requirements of cold storage, researchers have being considered the refrigeration system as a whole and studied the combined control methods for the main components (compressor, condenser, evaporator, and expansion valve) [7]. Theoretically, the combined control methods have better control effect. However, the nonlinear characteristics of the cold storage refrigeration system lead to the difficulty of dynamic modeling, the time-varying characteristics lead to the difficulty of control parameter online adjusting, and the coupling characteristics increase the complexity of the controller design [3]. Due to the difficulty of dynamic modeling, researchers employed control methods that do not need the accurate model of the system to get a better solution $[8,9]$, such as fuzzy control and neural network control. Based on the coupling characteristics of cold storage refrigeration systems, scholars proposed decoupling controllers, but it is hard to achieve the desired control effect due to the strong coupling.

Studies on control strategy with dynamic coupling compensation of cold storage refrigeration system were 
TABLE 1: The input and output variables and the state variables of the dynamic model.

\begin{tabular}{|c|c|c|}
\hline & Symbol & Name \\
\hline \multirow{2}{*}{ Input variables } & $f_{Y}(\mathrm{~Hz})$ & Frequency of the compressor \\
\hline & $A_{E}$ & Opening of the electronic expansion valve \\
\hline \multirow{2}{*}{ Output variables } & $T_{r i}\left({ }^{\circ} \mathrm{C}\right)$ & Temperature of the storage room \\
\hline & $T_{z o}\left({ }^{\circ} \mathrm{C}\right)$ & Outlet superheat of the evaporator \\
\hline \multirow{5}{*}{ State variables } & $h_{L}$ & Outlet enthalpy of the condenser \\
\hline & $h_{z}(\mathrm{~J} / \mathrm{kg})$ & Outlet ratio of enthalpy of the evaporator \\
\hline & $T_{r i}\left({ }^{\circ} \mathrm{C}\right)$ & Temperature of the storage room \\
\hline & $T_{L}\left({ }^{\circ} \mathrm{C}\right)$ & Temperature of the tube wall of the condenser \\
\hline & $T_{z}\left({ }^{\circ} \mathrm{C}\right)$ & Temperature of the tube wall of the evaporator \\
\hline
\end{tabular}

conducted. First, the dynamic model of cold storage refrigeration system was established, and the coupling was studied. Second, a fuzzy controller with dynamic coupling compensation was designed. The control strategy consists of a fuzzy controller, which served as the primary controller, and an adaptive neural network, which was adopted to compensate the dynamic coupling. Finally, the control strategy was applied to the control of a cold storage refrigeration system.

\section{Dynamic Coupling of Cold Storage Refrigeration System}

The working process of refrigeration systems is a nonlinear and strong coupling dynamic process with fusion heat transfer and mass transfer flow. The dynamic model is the basis of the simulation and the control system design. In this paper, with the consideration of the requirements of refrigeration control system, a nonlinear dynamic model is established. Models of the main components such as frequency conversion compressor, electronic expansion valve, condenser, and evaporator are established under the premise of idealized assumptions [10]. Assume that the fan speed of the condenser and the evaporator are constant and the control process can be realized by controlling the frequency of the inverter compressor and the opening of the electronic expansion valve. In addition, the temperature of the cold storage room is one of the most important controlled parameters, and the control of the evaporator outlet superheat is an important way to improve the stability and efficiency of the refrigeration system.

In the overall dynamic model, the input and output variables and the state variables are listed in Table 1.

Based on the energy equation of refrigerant in the condenser [11], the heat transfer energy equation of the condenser tube wall [12], the energy equation of refrigerant in the evaporator [11], the heat energy equation of the evaporator tube wall [11], and the dynamic model of the storage room [10], the dynamic model of the cold storage refrigeration system can be established. Ordering that $\mathbf{x}=$ $\left[h_{L}, T_{L}, h_{z}, T_{z}, T_{r i}\right]^{T}$ and $\mathbf{u}=\left[f_{y}, A_{E}\right]^{T}$, the dynamic model of the form of state space equation can be expressed as follows:

$$
\begin{aligned}
\dot{\mathbf{x}} & =\mathbf{f}(\mathbf{x})+\mathbf{g}(\mathbf{x}) \mathbf{u}, \\
\mathbf{y} & =\mathbf{h}(\mathbf{x}),
\end{aligned}
$$

where

$$
\begin{aligned}
& f(x) \\
& =\left[\begin{array}{c}
\frac{\alpha_{L i} A_{L i}}{m_{L}}\left(T_{L}-T_{z}\right) \\
\frac{\alpha_{L o} A_{L o}}{C_{L} L_{L}}\left(T_{r o}-T_{L}\right)-\frac{\alpha_{L i} A_{L i}}{C_{L} L_{L}}\left(T_{L}-T_{z}\right) \\
\frac{\alpha_{z i} A_{z i}}{m_{z}}\left(T_{z B}-T_{z L}\right) \\
\frac{\alpha_{z o} A_{z o}}{C_{z} L_{z}}\left(T_{r i}-T_{z B}\right)-\frac{\alpha_{z i} A_{z i}}{C_{z} L_{z}}\left(T_{z B}-T_{z L}\right) \\
\frac{\alpha_{r} A_{r}}{C_{r}+\rho_{k} C_{k} V_{r}}\left(T_{r o}-T_{r i}\right)-\frac{\alpha_{z} A_{z i}}{C_{r}+\rho_{k} C_{k} V_{r}}\left(T_{r i}-T_{z L}\right)+Q_{r}
\end{array}\right], \\
& \mathbf{g}(\mathbf{x})=\left[\begin{array}{ccccc}
g_{1}(\mathbf{x}) & 0 & 0 & 0 & 0 \\
0 & 0 & g_{2}(\mathbf{x}) & 0 & 0
\end{array}\right], \\
& g_{1}(\mathbf{x})=\frac{f_{\lambda} V_{y}(1-s)\left(h_{\mathrm{z}}+V_{c} f_{N \mathrm{th}}-h_{L}\right)}{p V_{c} m_{L}}, \\
& g_{2}(\mathbf{x})=\frac{f_{m v}\left(h_{L}-h_{z}\right)}{m_{z}}, \\
& \mathbf{h}(\mathbf{x})=\left[\begin{array}{c}
T_{r i} \\
T_{y}-T_{z L}
\end{array}\right], \\
& f_{\lambda}=0.98-0.085\left[\left(\frac{p_{i}}{p_{o}}\right)^{1 / k}-1\right] \text {, } \\
& f_{N \mathrm{th}}=p_{o} \frac{k_{E}}{1-k}\left[1-\left(\frac{p_{i}}{p_{o}}\right)^{\left(k_{E}-1\right) / k_{E}}\right] \text {, } \\
& f_{m v}=C_{E} \sqrt{2 \rho_{E}\left(p_{i}-p_{o}\right)} .
\end{aligned}
$$

The included variables are listed in Table 2.

In the refrigeration system, inverter compressors, electronic expansion valve, evaporator, and condenser and other components are not independent; the coupling can be described as in Figure 1. The two components of condenser and evaporator are connected with the indoor and external environment. The outdoor ambient temperature $T_{\text {ro }}$ influences the performance of the condenser, while the temperature of the storage room $T_{r i}$ and the refrigeration system are mutually restricted. The coupling between the expansion valve and the environment is indirectly connected through the condenser and the evaporator. 
TABLE 2: Variables and parameters in (2).

\begin{tabular}{|c|c|}
\hline Symbol & Name \\
\hline$\alpha_{L i}$ & Inner heat transfer coefficient of the condenser tube \\
\hline$m_{L}(\mathrm{~kg})$ & Weight of refrigerant in the condensing tube \\
\hline$\alpha_{L o}$ & Air side heat transfer coefficient of the condenser tube \\
\hline$C_{L}\left(\mathrm{~J} /\left(\mathrm{kg}^{\circ} \mathrm{C}\right)\right)$ & Heat capacity of unit length of the condensing tube wall \\
\hline$T_{r o}\left({ }^{\circ} \mathrm{C}\right)$ & Temperature of the outdoor ambient \\
\hline$\alpha_{z i}$ & Inner heat transfer coefficient of the evaporator tube \\
\hline$m_{z}(\mathrm{~kg})$ & Weight of the refrigerant in the evaporator tube \\
\hline$T_{z L}\left(\mathrm{~mm}^{2}\right)$ & Evaporation temperature of the refrigerant \\
\hline$A_{z o}\left(\mathrm{~mm}^{2}\right)$ & Heat transfer area of air side the evaporator tube \\
\hline$L_{z}(\mathrm{~mm})$ & Length of the evaporator pipe \\
\hline$A_{r}\left(\mathrm{~mm}^{2}\right)$ & Heat transfer area of the wall in the storage room \\
\hline$\rho_{k}\left(\mathrm{~kg} / \mathrm{mm}^{3}\right)$ & Density of the air \\
\hline$V_{r}\left(\mathrm{~mm}^{3}\right)$ & Area of the storage room \\
\hline$Q_{r}$ & Heat load of the objects in the storage room \\
\hline$V_{c}$ & Ratio of gaseous refrigerant in suction of the compressor \\
\hline$p$ & Magnetic pole logarithm of the motor \\
\hline$p_{\mathrm{o}}(\mathrm{Pa})$ & Outlet pressure of the electronic expansion valve \\
\hline$C_{E}$ & Flow coefficient of the electronic expansion valve \\
\hline$A_{L i}\left(\mathrm{~mm}^{2}\right)$ & Heat transfer area of the inner condenser tube \\
\hline $\mathrm{T}_{z}\left({ }^{\circ} \mathrm{C}\right)$ & Condensation temperature of the refrigerant \\
\hline$A_{L o}\left(\mathrm{~mm}^{2}\right)$ & Heat transfer area of the air side condenser tube \\
\hline$L_{L}(\mathrm{~mm})$ & Length of the condensing pipe \\
\hline$T_{L}\left({ }^{\circ} \mathrm{C}\right)$ & Temperature of the condensation tube wall \\
\hline$A_{z i}\left(\mathrm{~mm}^{2}\right)$ & Heat transfer area of the evaporator tube \\
\hline$T_{z B}\left(\mathrm{~mm}^{2}\right)$ & Temperature of the evaporator tube wall \\
\hline$\alpha_{z o}$ & Air side heat transfer coefficient of the evaporator tube \\
\hline$C_{z}\left(\mathrm{~J} /\left(\mathrm{kg}^{\circ} \mathrm{C}\right)\right)$ & Heat capacity of unit length of the evaporator tube wall \\
\hline$\alpha_{r}$ & Comprehensive heat transfer coefficient of the wall in the storage room \\
\hline$C_{r}\left(\mathrm{~J} /\left(\mathrm{kg}^{\circ} \mathrm{C}\right)\right)$ & Heat capacity of the objects in the storage room \\
\hline$C_{k}$ & Constant pressure specific heat of the air \\
\hline$\alpha_{z}$ & Comprehensive heat transfer coefficient of the evaporator \\
\hline$V_{y}$ & Swept volume of the compressor \\
\hline$s(\mathrm{r} / \mathrm{s})$ & Speed difference of the motor \\
\hline$p_{i}(\mathrm{~Pa})$ & Inlet pressure of the electronic expansion valve \\
\hline$k_{E}$ & Multidegree index \\
\hline$\rho_{E}\left(\mathrm{~kg} / \mathrm{mm}^{3}\right)$ & Density of inlet refrigerant of the electronic expansion valve \\
\hline
\end{tabular}

\section{Fuzzy Control with Dynamic Coupling Compensation}

Due to the complexity of the transfer process of quality and the energy, it is difficult to establish a precise mathematical model of refrigeration system. Furthermore, cold storage refrigeration system is a typical MIMO, strong coupling, time-varying, and nonlinear complex system; it is difficult to achieve the desired control effect through a SISO control method. Fuzzy control and neural network control are not dependent on the precise mathematical model of a control object, which are effective methods to deal with the uncertainty, nonlinearity, and strong coupling in a control system [13]. In this paper, a multivariable fuzzy neural network controller with dynamic coupling compensation is proposed.
The controller, which takes the advantages of fuzzy control and neural network control, is designed from the whole refrigeration system. The schematic diagram of the controller is shown in Figure 2.

As can be seen from Figure 2, the proposed controller is composed of a self-tuning fuzzy controller and an adaptive neural network coupling compensation controller. In the controller, the self-tuning fuzzy control determines the dynamic characteristics of the system, while the adaptive neural network control estimates the coupling of the multivariable.

The output deviation $e$ is transformed to the formal control variables $f_{Y}$ and $A_{E}$ by the self-tuning fuzzy controller. The formal control variables are the inputs of the adaptive neural network coupling compensation controller. The 


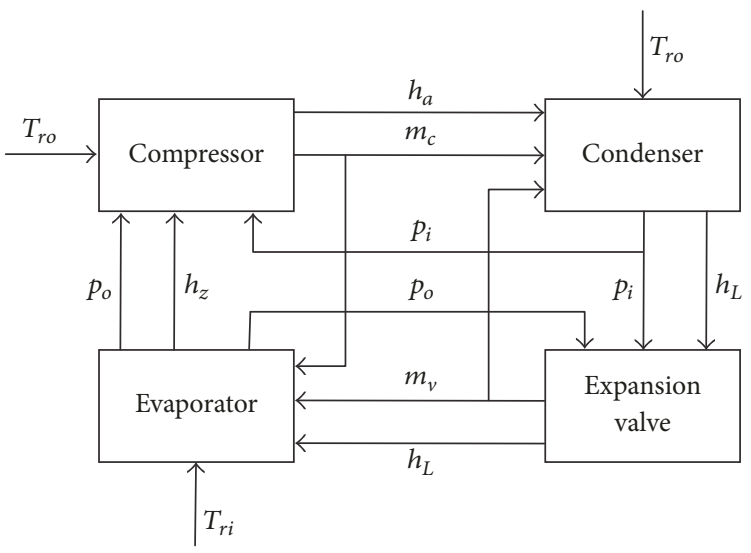

FIGURE 1: The coupling.

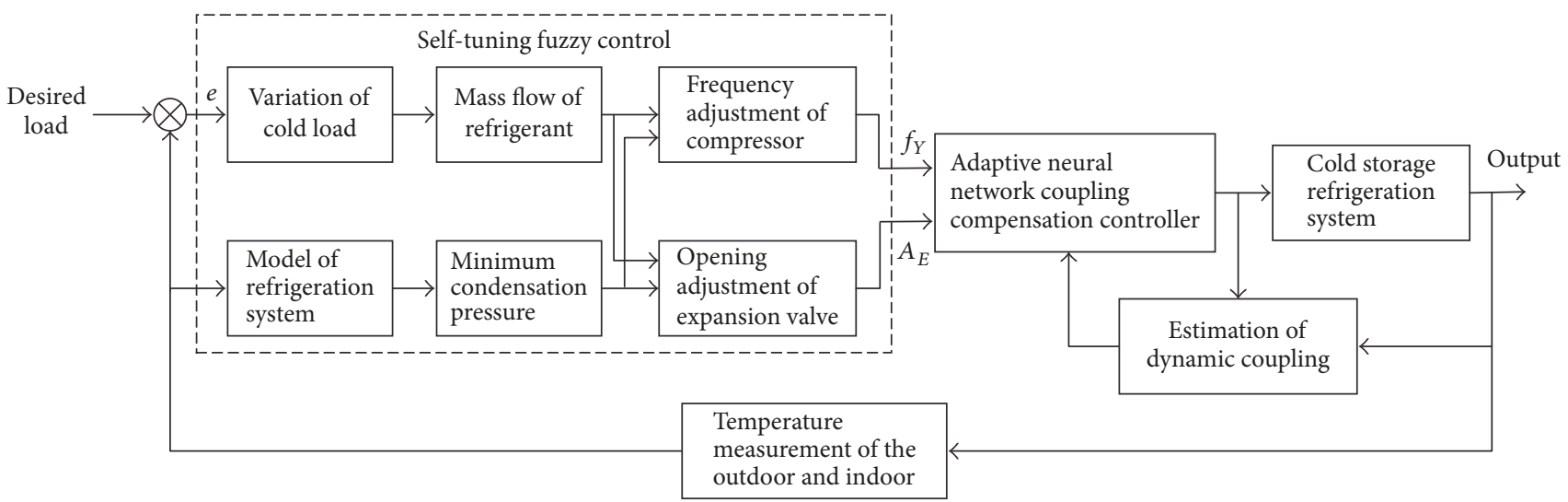

Figure 2: Fuzzy neural network controller with dynamic coupling compensation.

coupling effects are compensated as measurable disturbance. Through the dynamic coupling characteristic estimation and the neural network weights correction, the control object becomes a system with less coupling degree, and the output of the adaptive neural network coupling compensation controller is the input of the controlled object.

3.1. Self-Tuning Fuzzy Control. The intelligent weight function fuzzy algorithm is adopted to realize the self-tuning of the control rules. By using this method, it is not necessary to determine the membership function and fuzzy control rules of the fuzzy variables, and the interaction between other variables is not considered in the designed fuzzy controller. In a single loop of the self-tuning fuzzy controller, the selection of the fuzzy membership function is omitted, and the fuzzy quantity of the sampled discrete values $e(k)$ and $\Delta e(k)$ is multiplied by the quantization factors, shown as follows [14]:

$$
\begin{aligned}
E & =K_{E} e(k), \\
E_{C} & =K_{C} \Delta e(k),
\end{aligned}
$$

where $K_{E}$ and $K_{C}$ are the quantitative gains of the error and the error variation, respectively.

To ensure that the outputs of the weight function are meaningful when $E$ and $E_{C}$ are zero at the same time, the weighted factors of the error and the error variation are determined as follows:

$$
\begin{aligned}
& K_{E}=\frac{E}{|E|+\left|E_{C}\right|+\delta}, \\
& K_{C}=\frac{E_{C}}{|E|+\left|E_{C}\right|+\delta},
\end{aligned}
$$

where $\delta$ is a small positive number.

The rule of fuzzy control of intelligent weight function is

$$
\Delta U=K_{E} E+K_{C} E_{C} .
$$

The output of the self-tuning fuzzy controller can be expressed as follows:

$$
u_{0 i}(k)=K_{U} \Delta U+K_{I} \sum \Delta U
$$

where $K_{U}$ is the proportional gain and $K_{I}$ is the integral gain.

3.2. Adaptive Neural Network Coupling Compensation Control. Based on the output of the self-tuning fuzzy controller (there are two output variables), ordering that the weighted coefficients of the neural networks are $\omega_{i j}(i=1,2 ; j=1,2)$ and the output of the coupling compensation controller is 


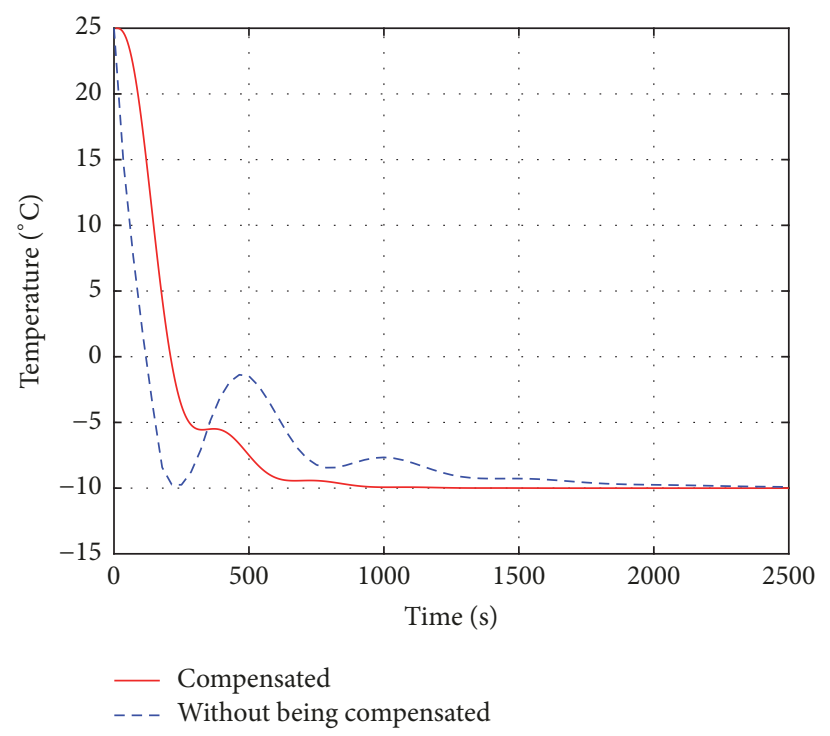

(a) The temperature of the storage room

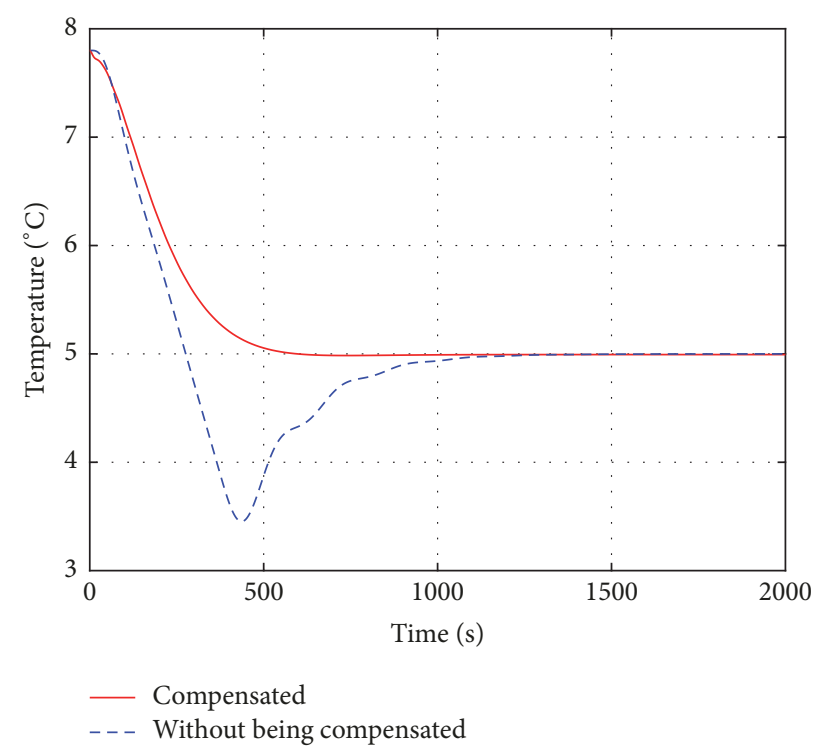

(b) The degree of superheat

Figure 3: Response curves after the system start-up.

$\mathbf{u}_{q}=\left[u_{q 1}, u_{q 2}\right]$, and the following relationship can be established [14]:

$$
u_{q j}(k)=\sum_{i=1}^{2} \omega_{i j}(k) u_{0 i} \quad(j=1,2) .
$$

The neural network and the controlled object are regarded as a whole, and the minimum value of the quadratic sum of the difference between the expected output and the actual one is used as the evaluation function of the system, shown as follows:

$$
E(k)=\frac{1}{2} \sum_{i=1}^{2}\left[r_{i}(k)-y_{i}(k)\right]^{2} \quad(i=1,2),
$$

where $r_{i}(k)$ is the desired value and $y_{i}(k)$ is the actual value.

In (8), the value of $E(k)$ can be minimized by online adjustment and self-learning of $\omega_{i j}(k)$. In the paper, the online adjustment method of $E(k)$ is referred to as the method in [15]. The self-learning of $\omega_{i j}(k)$ is completed by adopting the Gradient descent method, and the iteration value at time $k+1$ can be expressed as follows:

$$
\omega_{i j}(k+1)=\omega_{i j}(k)-\eta \frac{\partial E(k)}{\partial \omega_{i j}(k)},
$$

where $\eta$ is the learning rate.

Therefore,

$$
\frac{\partial E(k)}{\partial \omega_{i j}(k)}=-\sum_{i=1}^{2}\left[r_{i}(k)-y_{i}(k)\right] \cdot \frac{\partial y_{i}(k)}{\partial u_{q j}(k)} \cdot u_{0 i},
$$

where $\partial y_{i}(k) / \partial u_{q j}(k)$ is the rate of the affection of the $j$ th input $u_{q j}(k)$ on the controlled object in relation to the output. $\partial y_{i}(k) / \partial u_{q j}(k)$ can represent the dynamic coupling of the $j$ th input to the $i$ th output, and it can be calculated by the following equation:

$$
\frac{\partial y_{i}(k)}{\partial u_{q j}(k)} \approx \operatorname{sign}\left[\frac{y_{i}(k+1)-y_{i}(k)}{u_{q i}(k)-u_{q i}(k-1)}\right] .
$$

\section{Numerical Simulation}

To verify the effectiveness of the proposed control method for cold storage refrigeration system, numerical simulations were carried out. A small cold storage refrigeration system, which consists of R22 refrigerant, single-stage steam piston type compression refrigerator, electronic expansion valve, air-cooled evaporator, and air-cooled condenser, is taken as an example. In the study, $k_{E}=1.18$, the sizes of the cold storage room are $L \times W \times H: 4500 \mathrm{~mm} \times 3600 \mathrm{~mm}$ $\times 2700 \mathrm{~mm}$. During the process of simulation, the initial temperature of the storage room and the outdoor is $25^{\circ} \mathrm{C}$ and $30^{\circ} \mathrm{C}$, respectively, and the desired temperature of the storage room and the degree of superheat are $-10^{\circ} \mathrm{C}$ and $5^{\circ} \mathrm{C}$, respectively. After the system start-up, the response curves of the temperature of the storage room and the degree of superheat are obtained, as shown in Figure 3.

As can be observed from Figure 3, although the temperature of the storage room and the degree of superheat can reach the predetermined steady-state values with or without the dynamic coupling compensated, there are no overshoot and fluctuation if the dynamic coupling is compensated. In another case, the temperature of the storage room is dropped from $-10^{\circ} \mathrm{C}$ to $-15^{\circ} \mathrm{C}$, while the degree of superheat is still $5^{\circ} \mathrm{C}$, and the response curves are shown in Figure 4.

As can be observed from Figure 4, the curve of the temperature of the storage room is smooth without overshoot after the coupling compensated. Because of the rapid increase of the cooling load, the speed of the variable frequency 


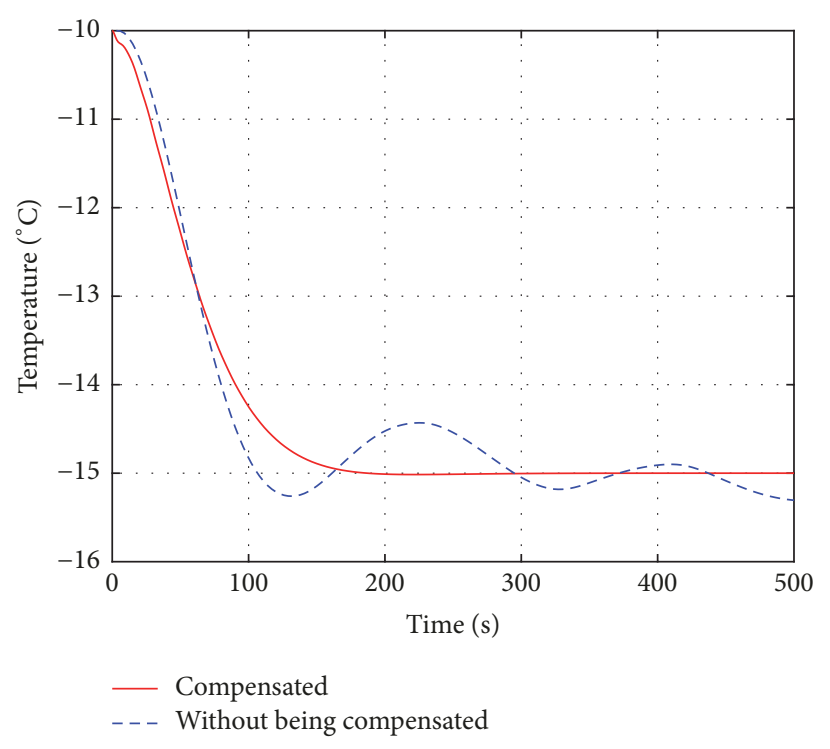

(a) The temperature of the storage room

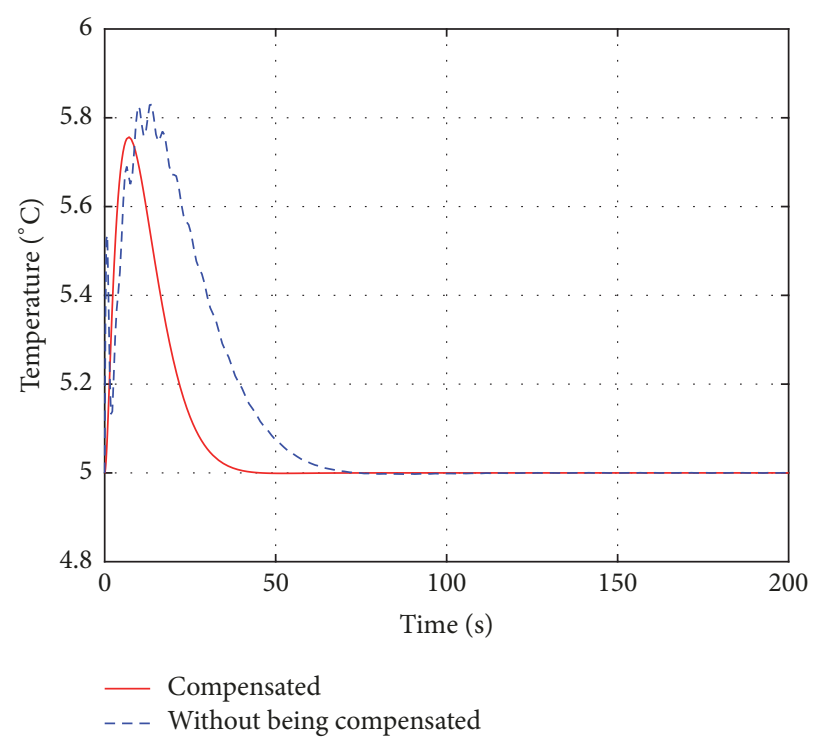

(b) The degree of superheat

FIGURE 4: Response curves when the load changed.

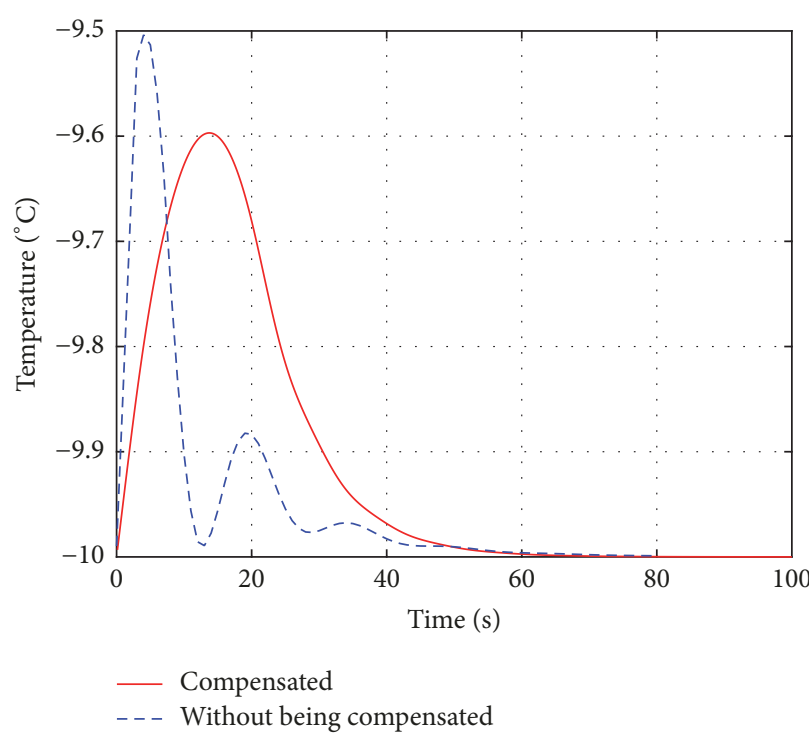

(a) The temperature of the storage room

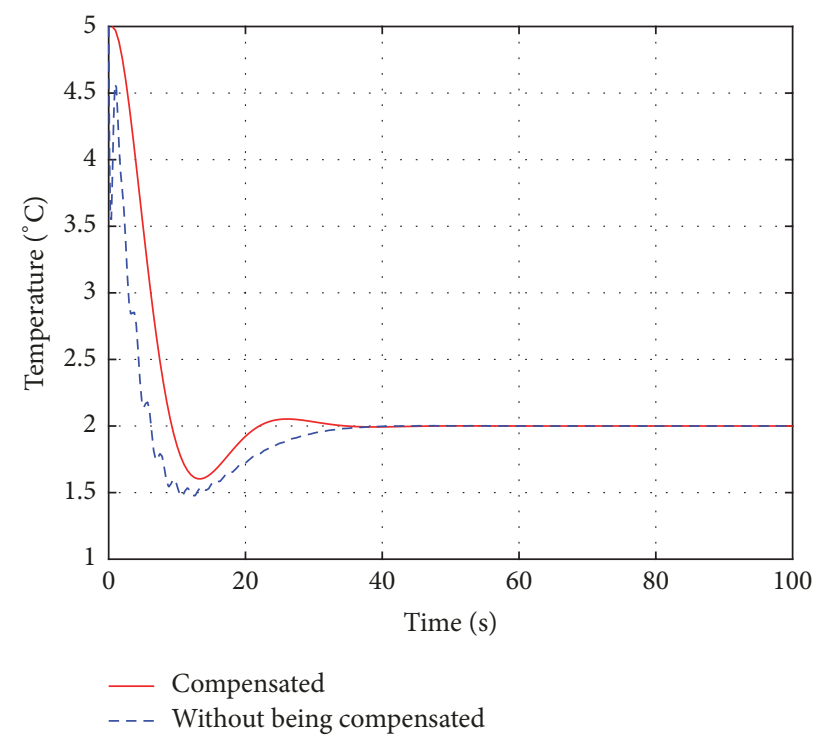

(b) The degree of superheat

FIGURE 5: Response curves when the degree of superheat changed.

compressor causes the expansion valve to be open too late to adjust, which leads to a certain fluctuation of the superheat. The comparison of the two results in Figure 4(b) shows that the proposed controller has a better tracking performance. In another case, the degree of superheat is dropped from $5^{\circ} \mathrm{C}$ to $2^{\circ} \mathrm{C}$ while the temperature of the storage room is still $-10^{\circ} \mathrm{C}$, and the response curves are shown in Figure 5.

As can be observed from Figure 5, when the degree of superheat changed, the change of the expansion valve causes the fluctuation of the temperature of the storage room, and the changing process is smoother if the coupling is compensated. Overshoot appears in the adjustment process of the degree of superheat, but the fluctuation is small and the control effect is satisfied.

\section{Conclusions}

In the paper, studies on control strategy with dynamic coupling compensation of cold storage refrigeration system were conducted. First, the dynamic model of cold storage refrigeration system was established, and the coupling was studied. Second, a fuzzy controller with dynamic coupling compensation was designed, the self-tuning fuzzy controller was the primary controller, and the adaptive neural network 
was used to compensate the dynamic coupling. Finally, the designed control strategy was applied to the control of a cold storage refrigeration system, and simulations were carried out in the condition of start-up, variable load, and variable degree of superheat, respectively.

As can be observed from the results of the simulation, in the condition of start-up, there are no overshoot and fluctuation if the dynamic coupling is compensated. In the condition of the variable load and the variable degree of superheat, the curve of the temperature of the storage room is smooth without overshoot after the coupling compensated, and the comparison of the results shows that the proposed controller has a better tracking performance. The simulation results indicate that the fuzzy controller with dynamic coupling compensation has good control performance and can be used in the control process of cold storage refrigeration system.

\section{Conflicts of Interest}

The authors declare that they have no conflicts of interest.

\section{References}

[1] N. D. Mukhopadhyay and E. S. Chowdhury, "Performance analysis of solar assisted cascade refrigeration system of cold storage system," International Journal of Advanced Research in Electrical Electronics \& Instrumentation Engineering, vol. 2, no. 4, pp. 1248-1254, 2013.

[2] A. Polzot, P. D’Agaro, P. Gullo, and G. Cortella, "Modelling commercial refrigeration systems coupled with water storage to improve energy efficiency and perform heat recovery," International Journal of Refrigeration, vol. 69, pp. 313-323, 2016.

[3] Y. P. Pan, Research on Multivariable Adaptive Fuzzy Control for Cold Storage Refrigeration Syste, Guangdong University of Technology, Guangzhou, China, 2007.

[4] J. Tian, R. Zhu, and Q. Feng, "Study on multi-variable fuzzy neural control for air cooled refrigeration system," Journal of Xian Jiaotong University, vol. 40, no. 5, pp. 514-517, 2006.

[5] T. Q. Chu and M. J. Lv, "Research on parameter-adaptive fuzzy controller for cold storage refrigeration system based on PLC, Refrigeration and Air Conditioning, vol. 8, no. 4, pp. 67-70, 2008.

[6] Q. S. Shao, X. W. Shi, T. X. Li et al., "Performance and control scheme of compressor and condenser in VRV air conditioning system," Compressor Technology, vol. 1, pp. 1-4, 2002.

[7] X. D. Wu, M. S. Jin, D. G. Fan et al., "Electronic expansion valvecompressor synchronous control," Fluid Machinery, vol. 33, no. 5, pp. 78-80, 2005.

[8] S. Li, T. Liang, X. Wang, and L. Kong, "Design for air conditioning evaporator superheat based on direct adaptive fuzzy controller," in Proceedings of the 2011 IEEE International Conference on Automation and Logistics, ICAL 2011, pp. 248253, China, August 2011.

[9] C. Gao, "Study on the energy-saving of cold storage based on fuzzy neural-network," Journal of Anhui Agricultural Sciences, vol. 39, no. 18, pp. 11213-11214, 2011.

[10] W. Chen, X. Z. Cai, and X. X. Zhou, "Modeling and control research of the triple-evaporator air-conditioner with inverter," Journal of System Simulation, vol. 16, no. 10, pp. 2123-2127, 2004.
[11] J. Z. Xie, MIMO Model And Decoupling Control of Refrigeration System, Xi'an Jiaotong University, Xi’an, China, 2001.

[12] J. Nyers and G. Stoyan, "A dynamical model adequate for controlling the evaporator of a heat pump," International Journal of Refrigeration, vol. 17, no. 2, pp. 101-108, 1994.

[13] M. Li, J. Y. Lin, and Y. G. Ma, "Adaptive neural non-model decouple control for MIMO system," Computer Simulation, vol. 6, no. 3, pp. 346-350, 2003.

[14] H. Li, "Design of multivariable fuzzy-neural network decoupling controller," Kongzhi yu Juece/Control and Decision, vol. 21, no. 5, pp. 593-596, 2006.

[15] Z. J. Zhou and Z. J. Han, "A New multivariable fuzzy self-tuning control system," Acta Automatica Sinica, vol. 25, no. 2, pp. 215219, 1999. 


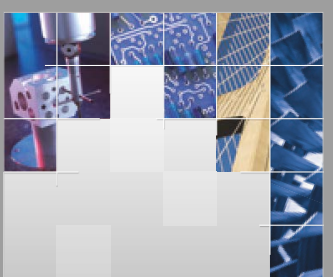

\section{Enfincering}
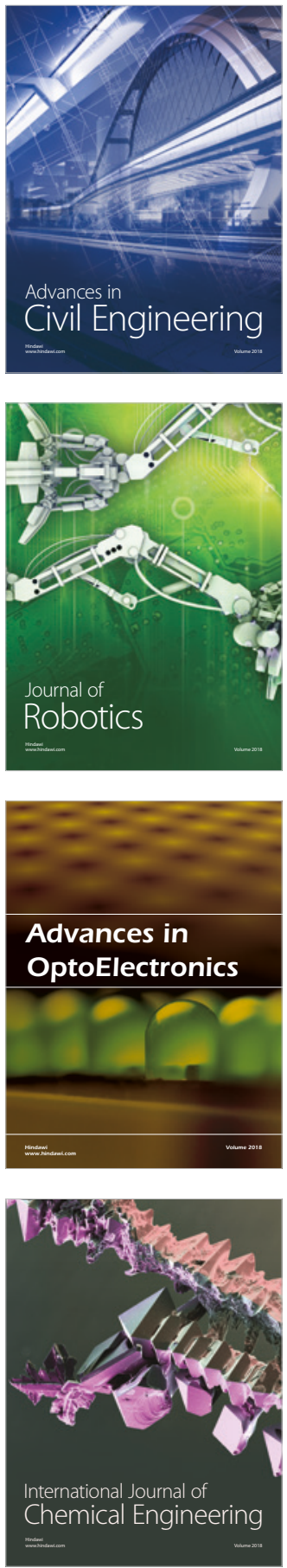

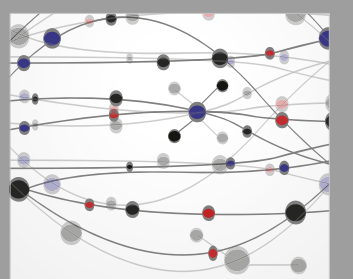

\section{Rotating \\ Machinery}

The Scientific World Journal

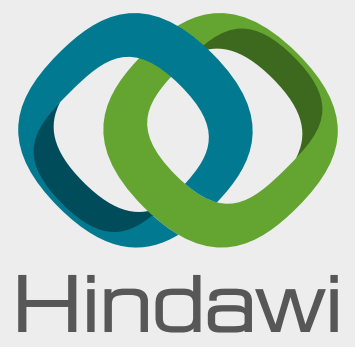

Submit your manuscripts at

www.hindawi.com
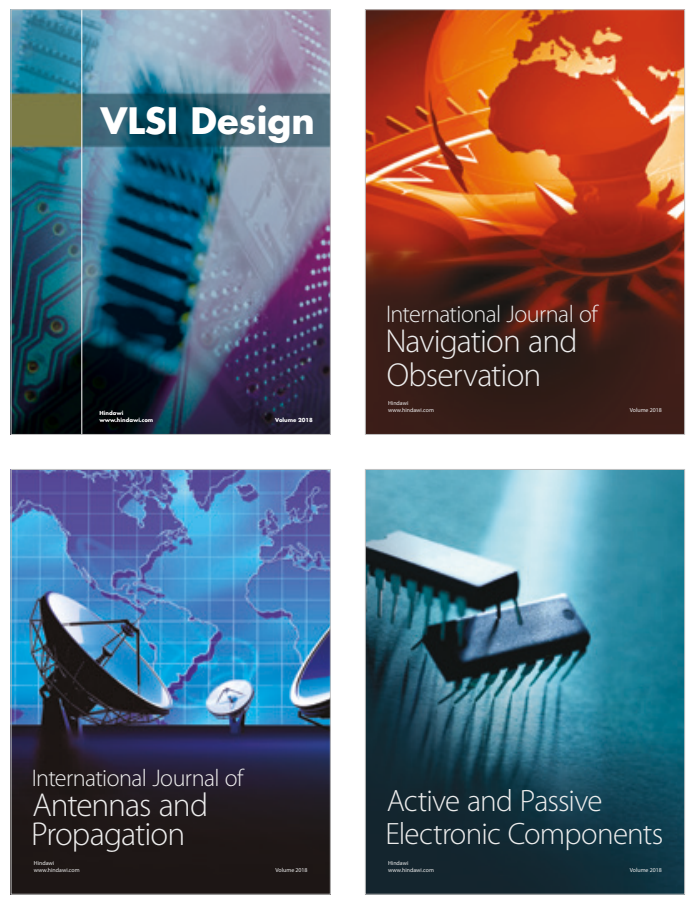
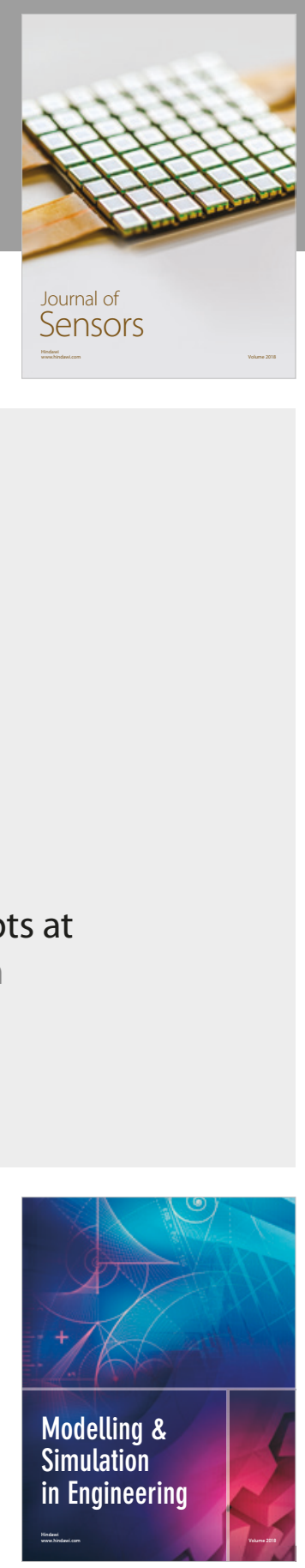

\section{Advances \\ Multimedia}
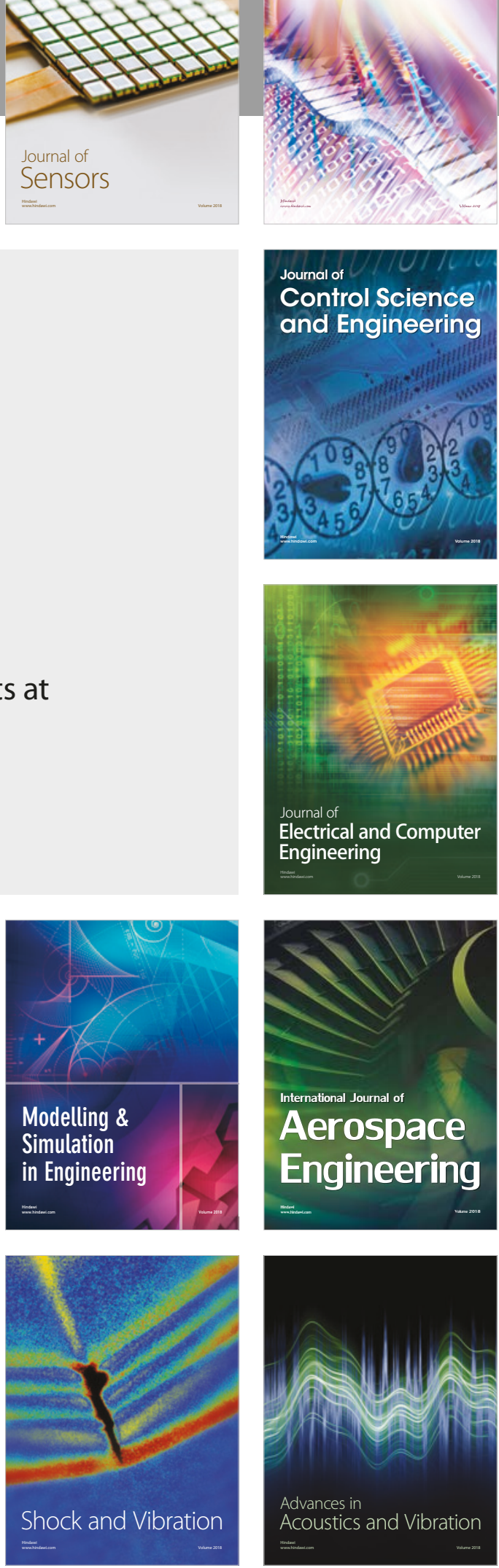